Each of these minute halospheres contains a nucleus accurately centred. If two such nuclei are sufficiently adjacent, the resulting halo is of the form of intersecting spheres. Three adjacent nuclei may give rise to a pear-shaped halo. There seems no doubt that their development is controlled by the nucleus in every case. As the bleaching is no objection to their radioactive origin, but in fact supports it, I see no alternative to the view that they are true haloes but of remarkably small dimensions. A prolonged search for other swarms of these haloes has proved unavailing.

It is of interest to notice that these haloes may benot impossibly-generated by one of the known elements, for they must originate from a substance so feebly radioactive that no known method of observation would detect its radioactivity. This follows from the extremely small trajectory of the responsible a-rays. It will be remembered that Rutherford long ago pointed out that there existed a connexion between the initial velocity with which an $\alpha$-ray was expelled and the period of the element giving rise to it. Geiger and Nuttall showed that a definite relation was deducible, most simply shown by plotting the logarithm of the constant of transformation against the logarithm of the range of the $\alpha$-particle. Thus treated, the elements of each radioactive family are distributed approximately along a specific right line, and the lines for the uranium, thorium, and actinium series are sensibly parallel. From this investigation Geiger inferred that elements emitting $\alpha$-particles of very small ranges would possess so slow a rate of transformation that no known instrumental method would reveal the fact that they were radioactive.

The age-long integration effected in the halo, however, can reveal radioactive phenomena far beyond the power of instrumental measurement. It is, therefore, not impossible that in these haloes we detect the radioactivity of some of those rare elements which this mica first revealed to science.

Lastly, one conspicuous fact is everywhere forced upon us in our studies of haloes-the scarcity of visible radioactivity in the rocks and the immense antiquity of that which we observe. In the absence of this mode of tracing radioactivity into the past, we might quite reasonably have argued that in former geological times many of the known elements were in process of radioactive genesis. The study of haloes rules out this view. Again, what radioactivity we are acquainted with has not originated in recent times. It dates back into the oldest rocks. The appearances which I have endeavoured to describe show this clearly. The reversed or blackened-up haloes of the Archæan are entirely different in appearance from those of Lower Palæozoic age. Indeed the geologist may by these appearances derive strong evidence as to the relative antiquity of the rocks he deals with. We arise from halo-study more than ever impressed with the immense age of the elements, and yet we know that some of them are to-day perishing off the earth and that a definite period is placed to their existence, What the halo ultimately shows is the remoteness of those past ages which probably witnessed the evolution of the elements.

\title{
The Malarial Treatment of General Paralysis.
}

GOR many years it has been realised that the intercurrence of an acute specific fever, such as erysipelas, in cases of general paralysis of the insane, is frequently followed by marked improvement in the general condition, and attempts have been made to procure remissions by the induction of an artificial pyrexia. In I9I 7 , von Jauregg introduced the method of inoculation with malaria. About 5 c.c. of blood are taken from the vein of a patient suffering from benign tertian malaria and immediately injected subcutaneously, intravenously, or intramuscularly into the general paralytic. The average incubation period is about ten days, after which typical malarial attacks appear. When the patient has passed through ten or twelve attacks, the malaria is arrested by the administration of quinine and a course of neosalvarsan is given. Improvement is observed soon after the cure of thie malaria, and in early cases of general paralysis the patient may become as capable as before the onset of the disease. Von Jauregg obtained prolonged remissions in more than fifty per cent. of his cases, the most noticeable features being the cessation of fits, better articulation, and general improvement in the mental and physical conditions. Other European observers have reported equally good results ; in a series of 296 cases, Gerstmann found remissions in sixty-eight per cent. ; Weigandt obtained improvement in forty-four out of fifty patients. In Great
Britain the number of patients hitherto treated is small; Worster-Drought found improvement in all except one of twelve early cases ; in a series of asylum patients, in whom the disease would be more advanced, improvement has been reported in six out of nine cases.

In dealing with syphilis of the central nervous system, the cerebro-spinal fluid affords an indicator of the inflammatory changes taking place in the brain and spinal cord, and the efficiency of treatment may be estimated by the resultant alterations in the fluid. So long as a positive Wassermann or any other abnormal reaction is given by the fluid, it cannot be considered that the disease has been eradicated. In cases of general paralysis, treatment by drugs has very little influence on these reactions; neither has it been found that inoculation with malaria, although producing remissions, has any effect in diminishing the intensity of the Wassermann and colloidal gold reactions. No patients have been observed for sufficient length of time to determine what period of improvement may be anticipated, but it must be remembered that spontaneous remissions are common during the course of general paralysis, and that relapses invariably follow. In view of the persistence in the cerebrospinal fluid of the evidence of active syphilis, it cannot be expected that remissions following malarial inoculation will differ from those which arise spontaneously.

$$
\text { No. } 2857 \text {, VOL. I } 14]
$$


In our present state of knowledge, only speculation is possible concerning the mode of action of artificial pyrexia. Drugs, and probably specific antibodies, penetrate with great difficulty into the central nervous system; it may be that pyrexia with leucocytosis in some way increases the accessibility of the actual nervous tissue to the passage of substances from the blood-stream. Purves-Stewart suggests that the remissions are due to the destruction in the febrile reaction of some of the toxins affecting the cerebral cells, the specific organism of the disease being unaffected. He has published descriptions of two cases of general paralysis treated by malarial inoculation, followed by a course of intra-cisternal injections of salvarsanised serum. In the resulting remissions the cerebro-spinal fluid became completely normal in one case, and the pleocytosis was markedly diminished in the other. This result is of great importance in indicating that malarial inoculation, combined with a specific anti-syphilitic treatment which can reach the cerebral cortex, may prove to be a means of completely arresting the disease.

Inoculation with malaria is not entirely without drawbacks; there is a definite risk of the parasite being conveyed to other persons by the mosquito; the Board of Control has issued a letter to asylum superintendents recommending a number of precautions to be adopted against this risk. In advanced cases the attack of malaria may hasten the fatal termination, but, in view of the hopeless prognosis of general paralysis, this mortality cannot be considered as a contra-indication to a treatment which in early cases produces such marked remissions. The serious nature of the disease, and the complete failure of anti-syphilitic treatment to have any effect on its course, demand that every endeavour should be made to investigate and perfect a method which offers some hope of improvement.

\section{Obituary.}

Sir William A. Herdman, F.R.S.

$\mathrm{T}$ HE sudden death of Sir William Abbot Herdman on July 2 I will be deeply regretted by naturalists in many parts of the world. For several years his general health had been bad. His only son, George, was killed in the battle of the Somme, and this calamity accentuated an illness from rheumatism which left him partially crippled and with serious heart weakness. He had begun to shake off the rheumatism when his wife died after two days' illness from pneumonia, and since then his health continued to be bad. He had gone to London on the day that he died to be present at the wedding of his daughter, and had arranged to leave Liverpool three days later for the British Association Meeting at Toronto.

Herdman was born at Edinburgh in 1858 , and was educated at the High School and University in that city. He graduated in science in 1879 , and was for a short time assistant to Sir Wyville Thomson. Then he went to the Challenger office, where he worked under Sir John Murray, and began the description of the Tunicate collections, a work which he finished at Liverpool. He went to the latter city in $\mathrm{I} 88 \mathrm{I}$, when the University College was established, as the Derby professor of natural history. In I9I9 he retired from his chair (then that of zoology), and became professor of oceanography, a post which he held for a year, when he retired as Emeritus Professor. His connexion with the University of Liverpool did not, however, cease in r92 $\mathrm{r}$ : he was a member of council and of various committees, and during the Lent term of r 924 he was acting vice-chancellor in the absence, on sick leave, of Dr. Adami. He had a room in the Department of Zoology, and he was there almost daily. At the time of his death he was engaged in a research on the morphology of Ramulina.

During the latter part of his life Herdman was a comparatively wealthy man, and (with his wife) was a generous donor to the University. He endowed the chair of geology in I9I6, and that of oceanography in 1919. In 1923 he gave the University a sum of NO. 2857 , VOL. I I 4$]$
$20,000 l$. to assist in the building of a new department of geology. He endowed an exhibition, and he bought and furnished a building at Port Erin as an institute and club for fishermen. For the last dozen years of his life he had become greatly attached to Port Erin, where he owned a house at which he resided during a considerable part of each year. His interest in Manx affairs was strong, and he was practically responsible for the foundation of the new Government Museum at Douglas.

Herdman's life-work was, of course, marine biology : that he began by a series of dredging expeditions in the Firth of Forth ; developed in the Challenger office, and continued when he went to Liverpool. There he found a small group of amateur naturalists whom he organised as the Liverpool Marine Biology Committee ; he outlived nearly all these original workers. They prosecuted active, systematic, biological investigations in the Irish Sea region, at first hiring steam tugs for their dredging and trawling expeditions. Then they fitted out a biological station at Puffin Island, in Anglesey, and later built two stations at Port Erin, in the Isle of Man. In I 892 Herdman organised the scientific work of the Lancashire Sea Fisheries Committee, and persuaded the latter body to found the Fisheries Laboratories at the University of Liverpool, and at Piel in Barrow. The result of these activities has been a very satisfactory biological survey of the Irish Sea, summarised in five volumes of a "Fauna and Flora," and a long series of papers on fishery subjects written by Herdman and his colleagues, and published by the Fisheries Committee. This work was, at first, financed locally, but, later, it was supported by government grants with results that have not been satisfactory. The local contributions have tended to decrease ; there has been an unnecessary control over expenditure, and an insecurity of tenure of post for the scientific men employed.

In I90I-2 Herdman went to Ceylon for the greater part of a year, at the request of the Colonial Office, to study the pearl-oyster fisheries. He went out again 